\title{
O programa de treinamento e de gestão de qualidade do mediador judicial e o direito
}

\section{fundamental de acesso à justiça}

The training and quality management program of the judicial mediator and the fundamental right of access to justice

El programa de formación y gestión de la calidad del mediador judicial y el derecho fundamental de acceso a la justicia

Felipe José Sousa Rodrigues ORCID: https://orcid.org/0000-0002-2264-4902 Instituto Superior de Educação - Centro de Mediadores, Brasil E-mail: felipejsr22@gmail.com

Sarah de Araujo Mendes Cardoso ORCID: https://orcid.org/0000-0003-0944-8154 Centro Universitário Santo Agostinho, Brasil E-mail: sarahamcardoso@gmail.com

Leandro Cardoso Lages

ORCID: https://orcid.org/0000-0001-8521-5649 Universidade Federal do Piaú, Brasil E-mail: leandrolages@ufpi.edu.br

\begin{abstract}
Resumo
A nova percepção de acesso à justiça está atrelada com o direito de participação de todos em procedimentos que estejam condizentes com a ordem jurídica pátria e resguardem direitos fundamentais. A nova abordagem do acesso à justiça está associada com os métodos de resolução consensual de conflitos, dentre os quais a mediação em um método autocompositivo de solução de desavenças, já que o poder decisório em relação à questão controversa pertence aos conflitantes e não a um terceiro. Com isso, para que haja plena abertura na obtenção de justiça por meio desse método adequado, o treinamento do mediador deve ser guiado e orientado para que haja qualificação teórica e prática em sua atuação, objetivando de forma efetiva a propagação da cultura de paz na sociedade. O presente artigo científico irá estudar o treinamento dos mediadores judiciais trazido pelo manual de mediação judicial elaborado pelo CNJ em 2016, com vista em concluir com a resposta à questão "o programa de treinamento e de gestão de qualidade do mediador judicial possui o potencial de assegurar o acesso à justiça?”. A metodologia do trabalho é uma revisão narrativa da literatura com busca, análise e síntese do conhecimento científico sobre o programa de treinamento e de gestão de qualidade do mediador judicial. Dessa forma, toda a organização que cerca o mediador é essencialmente qualificativa no que tange a busca pelo desenvolvimento do pleno acesso à justiça pela sociedade de forma igualitária e satisfatória. Palavras-chave: Métodos adequados; Mediação judicial; Treinamento do mediador; Gestão de qualidade; Competências do mediador.
\end{abstract}

\begin{abstract}
The new perception of access to justice is linked to the right of everyone to participate in procedures that are consistent with the national legal order and safeguard fundamental rights. The new approach to access to justice is associated with methods of consensual conflict resolution, among which mediation in a self-composed method of dispute resolution, since the decision-making power in relation to the controversial issue belongs to the conflicting ones and not to a third party. Thus, in order for there to be full openness in obtaining justice through this proper method, the training of the mediator must be guided and oriented so that there is theoretical and practical qualification in his / her performance, aiming at effectively the propagation of the culture of peace in society. This scientific article will study the training of judicial mediators brought by the judicial mediation manual prepared by CNJ in 2016, with a view to concluding with the answer to the question "the training and quality management program of the judicial mediator has the potential to ensure access to justice?". The methodology of the work is a narrative review of the literature with search, analysis and synthesis of scientific knowledge about the training program and quality management of the judicial mediator. Thus, the entire organization surrounding the mediator is essentially qualifying in terms of the search for the development of full access to justice by society in an equal and satisfactory way.
\end{abstract}

Keywords: Proper methods; Judicial mediation; Mediator training; Quality management; Skills of the mediator. 


\begin{abstract}
Resumen
La nueva percepción del acceso a la justicia está vinculada al derecho de toda persona a participar en procedimientos que sean compatibles con el ordenamiento jurídico nacional y protejan los derechos fundamentales. El nuevo enfoque de acceso a la justicia se asocia a métodos consensuados de resolución de conflictos, incluida la mediación en un método de autocomposición de resolución de conflictos, ya que el poder de decisión en relación al tema controvertido pertenece a las partes en conflicto y no a un tercero. Así, para que exista una apertura plena en la obtención de justicia a través de este método adecuado, la formación del mediador debe estar orientada y orientada para que exista una calificación teórica y práctica en su desempeño, apuntando efectivamente a la propagación de la cultura de paz. en la sociedad. Este artículo científico estudiará la formación de mediadores judiciales que trajo el manual de mediación judicial elaborado por el CNJ en 2016, con el fin de concluir con la respuesta a la pregunta "el programa de formación y gestión de calidad de mediadores judiciales tiene potencial para asegurar el acceso a la justicia?". La metodología de trabajo es una revisión de literatura narrativa con búsqueda, análisis y síntesis de conocimientos científicos sobre el programa de formación y gestión de la calidad del mediador judicial. De esta manera, toda la organización que rodea al mediador está esencialmente calificando en lo que respecta a la búsqueda del desarrollo del pleno acceso a la justicia por parte de la sociedad de manera igualitaria y satisfactoria.
\end{abstract}

Palabras clave: Métodos apropiados; Mediación judicial; Formación de mediadores; Gestión de la calidad; Competencias del mediador.

\title{
1. Introdução
}

A expressão "acesso à justiça" esteve por muito tempo associada apenas ao direito pela prestação jurisdicional efetiva e, por essa razão é necessário reforçar a desconstrução já existente desse significado limitante. Essa abordagem do acesso está expressa no inciso XXXV do artigo $5^{\circ}$ da Constituição Federal de 1988, a qual o elegeu como direito fundamental do ordenamento jurídico brasileiro. Dessa forma, ao realizar leitura de tal inciso é recomendado utilizar uma interpretação extensiva.

A nova percepção de acesso à justiça está atrelada com o direito de participação de todos em procedimentos que estejam condizentes com a ordem jurídica pátria e resguardem direitos fundamentais e, esses ritos procedimentais podem ser dos poderes executivo, legislativo e judiciário. Assim, os processos permitidos pelo direito brasileiro devem ser instrumentos que garantam a participação de seus usuários na edificação de decisões, as quais regulamentam e concretizam o exercício de direitos individuais e coletivos, em tempo razoável.

O significado da expressão foi ampliado da ideia de obter apenas um provimento jurisdicional satisfatório e devidamente cumprido em tempo hábil, assegurando o direito pleiteado junto ao poder judiciário, para a visão da existência de inúmeras opções de procedimentos que garantam a efetiva participação de seus usufruidores na geração de decisões resolutivas. Dessa forma, essa nova abordagem do acesso à justiça está associada com os métodos de resolução consensual de conflitos, dentre os quais a mediação.

A mediação consiste em um método autocompositivo de solução de desavenças, já que o poder decisório em relação à questão controversa pertence aos conflitantes e não a um terceiro. Dessa forma, o mediador exerce a função de um facilitador imparcial e neutro da comunicação, o qual irá estimular o diálogo empático entre as partes desentendidas para que elas possam gerar opções de soluções que compatibilizem os interesses de ambas.

Além de proporcionar a resolução de conflitos pontuais, a mediação possui a finalidade de ensinar as partes a solucionarem de forma pacífica futuros desentendimentos que possam surgir em qualquer relação interpessoal. Esse propósito educativo é obtido através da conduta do mediador ao conduzir o procedimento, já que o comportamento dele é de suma importância para repassar a essência da mediação que é o estímulo à cultura de paz. Assim, as partes entram em contato com um meio de resolução de desavenças cooperativo, em que é ensinado uma comunicação humanizada caracterizada pela escuta com o intuito de compreender e a fala com o viés de ser compreendido.

Na mediação as partes que se desentenderam possuem o poder decisório do conflito delas, ou seja, o processo é pautado no princípio da autonomia da vontade dos conflitantes. Dessa forma, as partes se tornam edificadoras da decisão que resguardará os seus direitos, criando um entendimento em ambas de que a resolução obtida foi justa e impedindo prováveis inadimplementos 
futuros. Além disso, a mediação gera a consciência de que todos são responsáveis pela existência do desentendimento e, em decorrência disso ensina às partes a mentalidade acerca das concessões que todos devem fazer para se ter uma boa convivência. Diante de tal raciocínio, a mediação gera um ambiente propício na constituição de cidadãos conscientes na manutenção da paz social.

A mediação está bem alinhada com a nova concepção de acesso à justiça e, seus propósitos de resolução pontual de conflitos e educação de cultura de paz estão intrinsecamente vinculados com a qualidade da capacitação do mediador. Esse profissional conduzirá uma comunicação empática entre as partes através de uma conduta pautada na urbanidade e, a utilização de inúmeras técnicas que ressignificam de forma positiva a situação conflituosa.

Essas habilidades devem ser aprendidas através de um treinamento, que inclui uma parte teórica e outra etapa prática através de simulações e um estágio supervisionado. Além disso, as instituições responsáveis pela realização das sessões de mediação devem promover programas de gestão de qualidade dos mediadores atuantes e, esse controle pode ser feito através do estímulo à formação continuada e à geração de pesquisas de satisfação dos usuários do serviço. Essa capacitação deve ser rigorosa e submetida a constante aperfeiçoamento para que o mediador saiba aplicar adequadamente as competências autocompositivas em desavenças com níveis distintos de polarização. Essas técnicas permitem que o mediador conduza uma comunicação reflexiva e compassiva capaz de romper o posicionamento adversarial das partes e gerar compreensão mútua. As competências autocompositivas são as seguintes: emocionais, cognitivas quanto ao conflito, perceptivas, de comunicação, de pensamento criativo e crítico, e de negociação.

O presente artigo científico irá estudar o treinamento dos mediadores judiciais trazido pelo manual de mediação judicial elaborado pelo CNJ em 2016, já que esse livro trouxe um modelo de capacitação a ser desenvolvido pelos NUPEMEC'S (Núcleo Permanente de Métodos Consensuais de Solução de Conflitos) de cada estado da federação; e esse treinamento pode servir também aos mediadores extrajudiciais que atuam em instituições privadas através de uma interpretação extensiva. Essa análise objetiva responder a seguinte indagação: O programa de treinamento e de gestão de qualidade do mediador judicial possui o potencial de assegurar o acesso à justiça? Com essa indagação, a pesquisa visa constatar a correlação entre a metodologia de capacitação do mediador judicial e a aplicação eficiente de competências autocompositivas necessárias a empoderar as partes na resolução de conflitos, promovendo o acesso à justiça através da satisfação nas soluções geradas.

\section{Metodologia}

A metodologia do trabalho é uma revisão narrativa da literatura, a qual compreende as seguintes etapas: busca, análise e síntese do conhecimento científico sobre o programa de treinamento e de gestão de qualidade do mediador judicial, com o escopo de constatar a sua relevância para a concretização do acesso à justiça e da cultura de paz pretendida pela mediação. O método de revisão narrativa consiste em uma análise ampla da literatura feita em curto lapso temporal, sendo recomendada para pesquisas que almejam descrever com víeis crítico um aspecto de determinado tema.

\section{Direito Fundamental do Acesso à Justiça}

De acordo com estudo realizado por Neto et al (2017), a construção do direito de acesso à justiça no Brasil é historicamente fundada na apreciação do Poder Judiciário, que inicialmente era tratado como mero ingresso ou fato de ajuizar uma ação, caracterizando o aspecto individual desse acesso à justiça, visto que as delimitações humanas não eram levadas em consideração. Porém, no mesmo estudo percebe-se que após a expansão das ideais propagadas pela Declaração Universal dos Direitos Humanos, muito do que se tratava individualista e privado foi sendo trabalhado como coletivo, humano e de responsabilidade conjuntamente estatal.

Pode-se assim enquadrar a definição do acesso à justiça seguindo percepção histórica e teórica a medida em que a 
sociedade se compõe e tece seus conflitos. Nisso, vê-se nas três composições básicas de Cappelletti uma compreensão não só cronológica dessa definição, como também de evolução do entendimento de resolução das desavenças surgidas dentro das relações sociais, assim como da participação dos agentes nesse processo de resolução, como o Estado, as partes envolvidas, o papel do advogado e mais recentemente, do mediador.

A delimitação usada por Cappelletti e Garth (1988), sobre a evolutiva percepção do acesso à justiça é cercada de reflexão acerca da necessidade em analisar o conflito sob ópticas psicossociais e humanas, as quais relacionaram ao incremento de outras áreas no funcionamento do sistema jurídico para que haja benefícios na busca pelo pleno sentimento de obtenção de justiça (Lages \& Diz, 2018). Assim, com essa intercessão de fatores, dividiu-se o entendimento desse acesso a três grandes fases e a uma concordância unânime sobre uma melhoria na ação judicial. As denominadas ondas do acesso à justiça iniciaram com a objetiva assistência judiciária que se caracterizou como ampla e buscou mecanismos de inclusão de pessoas em vulnerabilidade social no processo judicial, no entanto essa atuação judicial não pôde sozinha, reinterpretar e implementar um acesso real à essa população, resultando assim em comunidades ainda não alcançadas por essa prática, e que continuavam às margens do sistema judiciário.

Prosseguindo assim, a segunda onda levantou a necessidade em discutir com a sociedade sobre os obstáculos socioambientais e em fazer valer os direitos fundamentais relativos à igualdade. Com isso, a segunda onda absorveu a problemática acerca das barreiras do acesso à justiça aos grupos de representatividade específicos e coletivos, como encarcerados, ambiental, consumidores, reformulando a concepção do Direito Processual Civil e dos Tribunais, mudando o enfoque do direito individual para o pertencimento do direto a todos de igual modo. Contudo, os empecilhos não foram totalmente superados na segunda onda, resvalando uma terceira onda de urgências e carências no acesso à justiça de forma que o diálogo trouxe à cena o conjunto de mecanismos, sistemas e procedimentos que viabilizassem uma ampla variedade de reformas, que segundo Lages (2018), resumia-se em mudança na estrutura dos tribunais e criação de novos, estimulação de modificação no direito substantivo para evitar litígios, utilização de mecanismos privados ou informais de resolução dos litígios, alterações urgentes visto que o esgotamento do Poder Judiciário levaria à um colapso do pleno acesso à justiça igualitário e resolutivo.

Concomitante a isso, a Constituição brasileira de 88 inaugurou um marco histórico no ganho da concepção humana dos direitos fundamentais, identificando aqueles que seriam titulares dos direitos fundamentais ao adotar o princípio da universalidade e fornecendo subjetivamente cidadania aos processos desses direitos no acesso à justiça. Afirmação referenciada na letra da Carta Magna:

Art. $5^{\circ}$ Todos são iguais perante a lei, sem distinção de qualquer natureza, garantindo-se aos brasileiros e aos estrangeiros residentes no País a inviolabilidade do direito à vida, à liberdade, à igualdade, à segurança e à propriedade [...]

$\S X X X V$ - A lei não excluirá da apreciação do Poder Judiciário lesão ou ameaça a direito. (Constituição Federal, 1988).

Concebe-se assim o parâmetro normativo e o princípio da proteção judiciária no Brasil, assim como formação do vetor da dignidade da pessoa humana, quanto cidadão que possui acesso ao ordenamento jurídico, e não somente isso, mas também uma dimensão subjetiva desse direito fundamental de acesso à justiça, que busca superar as frustrações da prática jurídica com a evolução do conceito desse acesso, além do incentivo à formação de novas formas resolutivas e com o fomento à cultura de paz na sociedade (Macedo, 2017).

Pode-se inferir que o acesso à justiça como um direito fundamental do cidadão deve prezar em fornecer uma resolução acessível, igualitária e abrangente para as partes envolvidas, embasados na normatização da lei e buscando a integralidade subjetiva do conflito. Nisso, percebe-se falha e esgotamento do Poder Judiciário em suprir sozinho essas nuances sociais, visto que conforme discorrido anteriormente, é necessário que a obtenção da justiça esteja associada ao grau de satisfação em relação 
ao decidido sobre o conflito, o qual está relacionado com agentes inovadores na resolução de litígios e desavenças, sejam elas de caráter individual, coletivo ou de grupo específico. Assim, formas consensuais de solucionar os atritos carregam dispositivos que estimulam métodos nos quais as partes participam dos próprios resultados, possibilitando o empoderamento dos jurisdicionados e até mesmo uma maior celeridade nos processos (Suter \& Cachapuz, 2017).

Diante disso, tem-se na atualidade várias perspectivas de resolução de um conflito e partindo do referente jurisdicional há dois grupos importantes nesse debate: o judicial, onde a decisão é dirimida por um terceiro, o juiz, e o extrajudicial, o qual é subdividido em negociação, conciliação, mediação e arbitragem (Sales \& Rabelo, 2009; Martins \& Dobler 2020), dos quais a mediação será foco no presente artigo. A imposição das soluções normativas para resolver as divergências das partes é embasada constitucionalmente e fundamentada no discurso do Direito, porém ao entregar ao Judiciário número exorbitante de conflitos onde a decisão do terceiro é decisiva para promulgar decisão de paz se constitui em um dos maiores paradigmas no acesso à justiça. Logo, o caminho consensual da mediação ganha espaço em função da percepção do conflito como oportunidade de encontrar não uma solução imposta, mas sim construída pacificamente e conscientemente entre as partes.

\section{Resolução n 125/2010 do CNJ Como Marco Legal da Mediação}

Segundo teorização de Sales (2009), a mediação "é um meio não adversarial de solução de conflitos marcado pela interação de um terceiro", prioriza a gestão e o restabelecimento do diálogo entre as partes para que alcancem uma solução satisfatória sem a opinião do mediador em qual será o melhor caminho para a solução, mas sim auxilia a comunicação, visando aprofundar nas características reais do conflito. O mediador possui técnicas específicas na escuta, na observação e na verificação dos interesses subliminares nas acusações das partes, esperando atingir a compreensão do conflito e uma caminhada pacificadora para sua resolução.

O marco legal da mediação e dos métodos consensuais de resolução de conflitos no Brasil é determinado pela Resolução No 125/2010 do Conselho Nacional de Justiça, do qual algumas partes se seguem:

CONSIDERANDO que o direito de acesso à Justiça, previsto no art. $5^{\circ}$, XXXV, da Constituição Federal além da vertente formal perante os órgãos judiciários, implica acesso à ordem jurídica justa e a soluções efetivas;

CONSIDERANDO que, por isso, cabe ao Judiciário estabelecer política pública de tratamento adequado dos problemas jurídicos e dos conflitos de interesses, que ocorrem em larga e crescente escala na sociedade, de forma a organizar, em âmbito nacional, não somente os serviços prestados nos processos judiciais, como também os que possam sế-lo mediante outros mecanismos de solução de conflitos, em especial dos consensuais, como a mediação e a conciliação;

CONSIDERANDO a necessidade de se consolidar uma política pública permanente de incentivo e aperfeiçoamento dos mecanismos consensuais de solução de litígios;

CONSIDERANDO que a conciliação e a mediação são instrumentos efetivos de pacificação social, solução e prevenção de litígios, e que a sua apropriada disciplina em programas já implementados no país tem reduzido a excessiva judicialização dos conflitos de interesses, a quantidade de recursos e de execução de sentenças;

CONSIDERANDO ser imprescindível estimular, apoiar e difundir a sistematização e o aprimoramento das práticas já adotadas pelos tribunais;

CONSIDERANDO a relevância e a necessidade de organizar e uniformizar os serviços de conciliação, mediação e outros métodos consensuais de solução de conflitos, para lhes evitar disparidades de orientação e práticas, bem como para assegurar a boa execução da política pública, respeitadas as especificidades de cada segmento da Justiça [...] Art. $1^{\circ}$ Fica instituída a Política Judiciária Nacional de Tratamento adequado dos Conflitos de Interesses, tendente a assegurar a todos o direito à solução dos conflitos por meios adequados à sua natureza e peculiaridade.

Embasando-se no Manual de Mediação Judicial do Conselho Nacional de Justiça (2016), será discorrido sobre as definições, funcionalidades, objetivos e prática da Resolução 125 como marco legal na resolução de conflitos pela mediação.

Como parte do seu objetivo, a criação dessa resolução é fruto do entendimento que Políticas Públicas devem ser estabelecidas pelo Judiciário, nisso os meios heterocompositivos e autocompositivos são assim organizados em todo território 
nacional. Esse apoio, incentivo e sistematização das práticas autocompositivas é também foco da Resolução 125, disseminando assim a cultura de pacificação social com serviços autocompositivos de qualidade e gerando encorajamento à organização de tribunais em planejar programas amplos. Logo, a representação do Poder Judicial diante da sociedade deve ser reformulada, de um ambiente autoritário e sobrecarregado para um centro de resoluções efetivas e o distanciamento de formas e normativas excessivamente positivistas (Manual de Mediação Judicial, 2016).

Essa contemporânea compreensão de que o acesso à justiça se relaciona mais ao nível de satisfação do usuário substitui a percepção da justiça que recebe litígios e conflitos sem incluir os que estão à margem do sistema, tendo por base o que é "justo" diante de uma decisão ou mera ordem judicial em caso concreto, pois a participação das partes em algum momento desse processo é significativo para que a decisão e o acordo final seja encarado como justo e aceitável. Nesse aspecto o Manual de 2016 se embasa para afirmar que esse é um dos principais benefícios percebidos no movimento de acesso à Justiça, que efetiva o sistema com celeridade nos processos e com fomento à harmonia social.

De acordo com trabalho de Souza (2015), a atividade da mediação no Brasil já vem acontecendo de forma tímida mas avante nos estados da federação, sendo um serviço ofertado por mediadores independentes ou entidades que respondem ao serviço público (de viés lucrativo ou não), atividades essas variadas porém guiadas pela Resolução 125 de 2010. Assim, tanto as nuances da mediação prática quanto a capacitação do mediador são referenciados na Resolução 125 para que haja normativa objetiva nessa prática autocompositiva.

Outros aspectos quanto à Resolução 125 podem ser destacados como essenciais, dos quais a supervisão da atividade dos mediadores e conciliadores é de responsabilidade dos centros judiciais de solução de conflitos e cidadania, que são norteados por um Código de Ética próprio. Há também estabelecimentos de datas, prazos de finalização de um processo ou tutela de urgência, além de fundamentar as negociações buscando qualidade nos processos e o estabelecimento de competências autocompositivas indispensáveis nas seções e na formação do mediador.

À vista dessa exposição, destaca-se um último aspecto visto como essencial para esse debate, a necessária estruturação de supervisão e atuação desses métodos no Poder Judiciário: a criação do Núcleo Permanente de Métodos Consensuais de Solução de Conflitos (NUPEMEC), o qual é responsável por instalar os Centros Judiciários de Solução de Conflitos (CEJUSC). Fundamentados no art. $7^{\circ}$ da Resolução 125, esses núcleos tem por objetivo o desenvolvimento da política judiciária no local de atuação, utilizando-se a expressão informal de "cérebro autocompositivo", pois é responsável por capacitar magistrados, servidores, mediadores e conciliadores para qualificação do serviço entregue à população.

\section{Mediação como Instrumento de Efetiva Realização da Justiça}

Conforme exposto da evolução histórica e teórica do acesso à justiça, é possível assim afirmar que nas sociedades atualmente vigentes o tradicional formato Judiciário possui morosidade e carga excessiva de litigiosidade, o que caracteriza a justiça como inapta para as urgências dos conflitos inter-relacionais e sociais. Contudo, é possível visualizar uma construção de resolução mais próxima das transformações sociais, como o aspecto autocompositivo pela participação das partes, a humanização do conflito e suas nuances nas relações pessoais e coletivas e o incentivo à cultura de paz na sociedade, sendo essas modificações atreladas tanto no âmbito judicial quanto extrajudicial.

Em pesquisa realizada por Sales e Andrade (2011), a necessidade de novas abordagens de solução dos litígios como resultado da transformação da sociedade é um movimento que não só abre espaço para o acesso à justiça como também valoriza o cidadão e seu papel na manutenção de uma esfera jurisdicional qualificada e apta. A concepção dessa participação do cidadão implica em condições de reconhecimento, dignidade e empoderamento do domínio de seus direitos, o que potencializa uma das premissas universais dos Direitos Humanos que é a igualdade. Nisso, se concebe o cidadão em forma prática aquele que além dos direitos e garantias socioambientais, possui também acesso aos meios processuais perante o Poder Público, o que se dá na 
contemporaneidade através das variadas formas de facilitar e engajar essa obtenção de solucionar litígios de forma pacífica, participativa e mais célere.

A mediação se predispõe sobre a prática do acesso à justiça centrada nas partes, em seus diálogos, objetivos, interesses subjetivos e disposição em encontrar possíveis soluções. Por meio tradicionalmente judicial o diálogo entre as partes é constantemente perdido e prejudicado pelas características antes enunciadas, o que se difere da mediação, na qual durante o processo de busca da solução há um estabelecimento de técnicas, direcionadas pelo mediador, que auxiliam a construção de uma conversa clara, objetiva e humana. Com isso, há o avanço na resolução do litígio em si, pois os interesses podem ser expostos e avaliados, sem que haja parcialidade ou preferência de ganho em uma das partes em questão, coagindo para uma solução que agrada racionalmente ambos e responsabiliza não um terceiro pela conclusão do caso, mas sim os participantes do conflito (Sales \& Andrade, 2011; Corrêa, et. al. 2021).

É de suma importância social que o desenvolvimento da mediação seja visto como requisito fundamental no acesso à justiça igualitário, efetivo e garantidor da manutenção dos direitos do cidadão, pois uma nação constituída por um judiciário democrático e à disposição do seu povo representa uma nação moderna que viabiliza o desenvolvimento social. Por essa perspectiva é na mediação do conflito que o cidadão encontrará respostas para seu próprio levantamento de demandas, diminuindo assim a distância entre a democracia teórica e a efetivação das garantias individuais e coletivas da população.

\subsection{Atuação da mediação nas esferas sociais}

A mediação se revela de formas variadas na sociedade, visto que seus métodos podem ser aplicados nos âmbitos que circundam as relações sociais, nas quais o conflito aparece em prol de demandas financeiras, psicológicas, divergência de interesses e até mesmo na atuação de uma equipe que organiza um setor público. Dessa forma, será exposto estudos e pesquisas embasados em relatos de caso e de experiência, onde a mediação cumpriu papel decisivo na resolução dos problemas, emancipou a harmonia nas relações mediadas e possibilitou pleno acesso à justiça.

Em estudo feito por Camargo (2017), muitos conflitos comunitários podem ser guiados por sessão de mediação comunitária, onde o mediador é indicado pela comunidade para atuar de forma imparcial e orientar a resolução justa da adversidade estabelecida. É defendido pelo autor, que como um método diferenciado dos demais por ser um exercício claro de cidadania, a mediação comunitária usa um papel de educador social na construção de valores coletivos e de independência da comunidade diante de seus próprios conflitos. O mediador assim, como sujeito neutro, ausente de poder decisório, imparcial e possuidor das capacidades técnicas de sua formação, auxilia as pessoas a alcançarem acordos satisfatórios para as partes envolvidas, sendo uma ferramenta de acesso à justiça. Outro benefício da mediação comunitária está em caracterizar o mediador como conhecedor da realidade da comunidade, o que lhe humaniza uma vez mais diante de tal conflito, gerando na comunidade a sensação de plena compreensão por quem lhes auxilia no acordo findado. Essa atuação dá qualidade ao judiciário, pois evita enfrentamentos violentos, incentiva participação ativa sem a existência de "perdedores" ou "vencedores" e viabiliza um caminho prático de cidadania. Logo, dentro da comunidade a compreensão de obtenção de justa resolução de um conflito deixa de ser sinônimo de "ação judicial", passando pela compreensão de que os litígios não necessitam da morosidade do tradicionalismo do Poder Judiciário para serem analisados, mas sim de resoluções efetivas e agregadoras da cultura de paz entre a população. Fortalecendo esse ambiente comunitário, o CNJ incentiva o programa de Justiça Comunitária, fornecendo o conhecimento dessa ferramenta em diversas regiões do país.

Muitos conflitos que envolvem o setor trabalhista movimentam-se no mero desacordo de verba que viola a moralidade do trabalhador, possuindo repercussão emocional, visto que é um conflito que se estabelece entre realidades e esferas distintas da sociedade (Vasconcelos et al, 2020). Logo, a tolerância diante das diferenças entre as partes é efetivada na utilização de soluções restaurativas e autocompositivas, pois pode viabilizar a reintegração funcional, o qual tem-se na mediação judicial 
trabalhista forte escopo e praticidade, sendo uma alternativa eficiente e segura em concretizar resolução de ordem moral que envolve um conflito. No entanto, no estudo observou-se que nem todos os conflitos levantados por autores de classificação distinta dentro da sociedade podem ser resolutivos de forma dialogável ou consensual, já que a escolha da pacificação diante da solução de um problema deve partir principalmente do interesse das partes, porém afirma-se que a praticidade da restauração do conflito não perpassa apenas no acerto, na conclusão ou na solução, mas para além disso, viabiliza a educação das partes enquanto civis, o fomento do respeito às dignidades e à autogestão pelo caminho não violento de comunicação; aspectos que caracterizam o método da mediação por ser dialogável, empático e que prioriza a tolerância em busca da paz social (Teixeira, et al. 2020).

Segundo pesquisa de Gago \& Sant'Anna (2017), a comunicação incentivada pela mediação, identificada como nãoviolenta, é essencialmente protagonista nos acordos familiares durante processos judiciais, à vista de que no decorrer das fases da sessão de mediação a comunicação procura identificar as necessidades e diferenciá-las do sentimentalismo exacerbado, promovendo espaço para que as partes exponham os interesses de forma total e compreendam a objetividade da resolução. A narrativa exposta pelos participantes de um caso revela o direcionamento que o mediador deve utilizar para que seja alcançada não só a sensação de resolução justa e eficaz para ambos litigantes, como também na transformação da comunicação fragmentada existente no núcleo familiar em um diálogo claro, aberto e que funcione como ferramenta na harmonia decisória da família.

Um outro âmbito social que requer atenção da mediação para alcançar a obtenção de justiça é o ambiente escolar, o qual perpassou por profundas alterações históricas, culturais e de metodologias de ensino e aprendizagem. De acordo com Paraventi et al (2017), as relações escolares que evocam queixas atravessam aluno, professor, o conteúdo lecionado e pais, por onde a mediação se utiliza de intervenções acolhedoras para gerar vínculos em que cada atuante nessa esfera possua seu papel visível e exato, pois é observável que na dinâmica do relacionamento escolar haja constante fuga da compreensão de que "educação" possui vertente técnica, oferecida pela escola de forma sistemática, e emocional, fortalecida pela família. Na exposição analisada, a mediação construiu a percepção de que a conversa em sala de aula é fundamentada na necessidade de participação ativa do aluno no seu próprio processo de ensino e aprendizagem, análise que educou professores e alunos no desempenho de autoavaliação e autorregulação. Ademais, a intervenção do mediador pôde ressignificar o conflito escolar de forma contextualizada, humana e equilibrada para que ambas necessidades e interesses fossem atendidos e ajustados.

Em uma última explanação da mediação como prática de acesso à justiça nas variadas esferas sociais, há no setor administrativo a necessidade da atuação da mediação, pois pode-se depreender que o conflito pode proporcionar um ambiente organizacional caótico e de difícil aplicação das funções nele estabelecidas, uma vez o trabalho que é desenvolvido em equipe e possui estruturação em rede demanda de sistematização e espontaneidade. Segundo Mussio \& Serapião (2017), a atividade empresarial e de secretariado requer tanto dedicação de seus funcionários, quanto evolução do serviço que é oferecido através da formação contínua dos colaboradores, ambas exigências que precisam de disposição, flexibilidade e compromisso, os quais podem ser classificados como qualidades que são dimensionadas de forma subjetiva, o que se torna alvo de desentendimentos por ausência de uma prática de comunicação não violenta. Diante disso, a mediação pode prevenir conflitos graves para o funcionamento padrão da empresa e para a integridade moral das partes envolvidas com o estímulo ao desenvolvimento de inteligência emocional da equipe, pois as dinâmicas humanas devem ser consideradas importantes no setor organizacional, aperfeiçoando assim as relações interpessoais de tal empresa e da rede de trabalho.

\section{Programa de Treinamento e de Gestão de Qualidade do Mediador Judicial}

O enfoque dado pelo Manual de Mediação Judicial (2016), para a gestão de qualidade da mediação é consequência da busca de melhorias e padronizações nos serviços dos mediadores, essa tendência tem por objetivo ampliar os resultados da mediação, reduzir conflitos comerciais e custos com os litígios, além da preservação de relações importantes dentro da sociedade. Dessa forma, os usuários do método autocompositivo devem avaliar o serviço como satisfatório para que haja mensuração da 
qualidade esperada pela mediação, e assim o papel do mediador é intrínseco no atributo qualificador da resolução de conflito.

Concomitante a isso, as metas de um programa de gestão de qualidade perpassam pelo treinamento do mediador em efetivar as habilidades do método adequado tendo, porém, na variância dos treinamentos ofertados pelos tribunais a necessidade de uma estruturação base para constante avanço do serviço ofertado à população. Diante disso, as atribuições do mediador formadas ao longo de sua formação e treinamento coincidem para o desenvolvimento do campo de comunicação que proporcione resoluções adequadas de conflito. Nisso, a relevância da temática do presente estudo emerge para a caracterização desse treinamento, a qualificação do mediador diante dos processos conflitantes e as competências indispensáveis que devem ser desenvolvidas e constantemente aperfeiçoadas no mediador.

\subsection{Atuação do NUPEMEC e a relevância do treinamento do mediador de conflitos}

A teorização do treinamento do mediador dispõe sobre aspectos relevantes na sua atuação e no desenvolvimento de suas habilidades práticas. Discorrer-se-á assim embasamento técnico-científico que envolve o treinamento do mediador.

De acordo com análise de Rubén Calcaterra (2002), a formação do mediador não pode ser compreendida como exercício simples, mas complexo por se tratar de habilidade que envolve desenvolvimento pessoal em primeiro lugar, seguido de percepções profissionais e sociais concatenadas e em constante mudança. Além disso, o futuro mediador não só atuará conforme as nuances subjetivas das partes, como também de forma objetiva nos acordos que finalizarão o processo, por isso a experiência da prática desse método alternativo pressupõe uma ampliação da capacidade de neutralidade do mediador, visto que essa característica dá base pessoal e profissional diante das mudanças na sociedade e nas formas de resolução de um conflito.

Desse modo, a experiência é vista como essencial no treinamento do mediador, pois a neutralidade deve ser praticada de forma contínua (Fisher, 1969; Leitão, 2021). E essa experiência é para Six (2001), ferramenta de conhecimento do tempo gasto com cada conflito, tanto para exposição dos interesses e necessidades das partes, quanto para concatenação dos fatos relevantes na sessão que serão evidenciadas pelo mediador no momento da fundamentação do acordo. Por isso, a adaptação em cada caso é uma construção constante realizada de forma cada vez mais eficiente pelo mediador a medida que o mesmo se expõe à praticidade dos processos. Essa concepção ainda é levada em bastante consideração pelos teóricos, como afirma Pinho (2011), que "a mediação é um trabalho artesanal", pois a análise de cada caso demanda aprofundamento em questões únicas que correspondem nas partes envolvidas do conflito, sendo o mediador um terceiro neutro que precisa compreender o peso emocional do confronto.

Segundo Bush e Folger (2004), em seu livro "A promessa de mediação: a abordagem transformadora do conflito", defende que o treinamento do mediador deve conter em sua estruturação a promoção do valor da mediação, sua capacidade de intervir em conflitos e de transformação da própria sociedade em agente de pacificação, mesmo que a longo prazo. $\mathrm{O}$ esclarecimento fixante dessa compreensão valorosa da atuação do mediador é essencial para uma prática de excelência e de geração de frutos jurídicos e sociais. Além disso, o cliente que participa de uma sessão de mediação precisa estar ciente e confiante de que há diferenciação desta com um processo judicial tradicional heterocompositivo, pois assim avaliarão esse método como enriquecedor jurídico, ético, social e humanitário.

A capacitação aqui defendida como primordial no sucesso e evolução da mediação é vista por Souza (2015), como substancial para aprimoramento da seriedade, responsabilidade e profissionalismo de um mediador em sua atuação, sendo encarregado de oferecer serviço qualificado para os usuários. Em tal caso, a imparcialidade e a manutenção do equilíbrio entre as partes estão relacionados diretamente com a validade de qualquer programa de mediação ou conciliação, não podendo ser assim um aspecto subestimado no treino de tal operador desse serviço.

Embasando-se dessa forma nos teóricos citados, a seleção, a capacitação técnica, a observação, a supervisão do serviço prestado e a avaliação do usuário são aspectos relevantes no treinamento do mediador judicial, o qual é normatizado e orientado 
pelos NUPEMECs, apoiados na publicação do Manual de Mediação Judicial, publicado pelo Ministério da Justiça.

Para exemplificação da atuação de um NUPEMEC, utilizar-se-á base científica no trabalho realizado por Albuquerque (2017). É de responsabilidade do NUPEMEC ofertar cursos especializantes na capacitação de mediadores e conciliadores para futura atuação na sociedade. Para inscrição efetiva de um cidadão há requisitos normativos a serem preenchidos pelo candidato, como por exemplo ser servidor do Poder Judiciário ou aposentado, ou ainda, pessoas físicas possuidoras de diploma de graduação de no mínimo dois anos, tais requisitos não são perceptivelmente variantes em cada região do país. Durante a capacitação, é desenvolvido certos objetivos pedagógicos fundamentais na atuação do mediador, como identificação de uma mediação satisfatória ao usuário, incentivo da busca em melhorias pessoais e inter-relacionais contínuas, conhecimento teórico da autocomposição, demonstração da atuação harmônica de um terceiro neutro, condicionamento de que o conflito é natural dentro das relações estabelecidas na sociedade, compreender as falas e as reações ao conflito como resultado cultural, estimulação da resolução de um conflito como sendo positivo para pacificação das partes, além das habilidades técnicas que cercam a declaração de abertura e seu exercício durante as seções estabelecidas.

Outrossim, a qualificação de um mediador judicial, de responsabilidade do NUPEMEC, também deve fortalecer a comunicação não violenta na forma atuante do mediador, pois ao guiar uma sessão há necessidade de diferenciação entre interesse real e aparente, a validação de sentimentos e possibilitar que eles sejam identificados também pelas partes, despolarizar as falas exercendo empatia para ambos litigantes com o uso de uma linguagem neutra, educar os participantes quanto à situações de impasse, principalmente em questões financeiras, conduzir a contextualização da decisão informada, e finalmente proporcionar que o mediador veja na gestão de qualidade uma melhoria contínua de sua própria técnica. Em consequência dessa formação, o estágio e a futura prática de mediação são orientadas pelos CEJUSCs locais em que cada mediador viabilizará sua participação.

\subsection{Manual de mediação do CNJ, a promoção da cultura de paz nos CEJUSCs e as qualidades nos processos autocompositivos}

O CNJ através do Manual de Mediação traz orientações e sugestões para guiar a formação do mediador judicial, pois é de igual importância a propagação da mediação como benéfica na sociedade quanto também o treinamento eficiente de mediadores atuantes e habilitados na prática. A atenção do CNJ quanto a preparação do mediador perpassa por enfoques para além do fim do conflito, mas antes busca dedicação quanto à pacificação e socialização entre as partes, nisso as competências para atuação plena devem ser desenvolvidas ao longo do curso, de forma concatenada e evolutiva, desde nível básico, intermediário e avançado com a observação e prática.

No próprio documento do Manual (2016), é indicado linhas de qualidade que devem ser seguidas no treinamento do mediador, a técnica, principalmente autocompositivas que resvalam na satisfação do usuário, a ambiental, espaço físico adequado e harmônico em que a mediação será conduzida, a social, comunicação e relacionamento entre as partes e delas com o mediador, e a qualidade ética, a conduta esperada pelos praticantes da mediação que atendem o usuário. Assim, o pragmatismo da sessão pode ser variável conforme o mediador, qual for narrativa, circular-narrativa, transformativo-reflexivo, dialógica ou outro, sendo porém inevitável a execução de técnicas e ferramentas gerais, como gerenciar um processo autocompositivo concretamente, deferir negociação objetivando o findar do conflito, guiar as partes para a resolução dos próprios desentendimentos através da fala, interesses e sentimentos expostos, e a constante formação ética do referido mediador. Dessa forma, pode-se resumir uma boa formação em cinco pilares que se seguem: processo seletivo, capacitação técnica, ambiente de observação, supervisão e constantes avaliação pelo usuário.

Conforme pesquisa de Lima et al (2018), os Centros Judiciários de Solução de Conflitos e Cidadania (CEJUSCs) se constituem como meio de realização de sessões de mediação para a comunidade, de forma acessível economicamente para as 
partes interessadas no serviço, o que favorece à população acesso à justiça cada vez mais igualitário e efetivo, visto que a hipossuficiência é um fator preponderante para a existência de cidadãos à margem do pleno acesso ao judiciário. Desse modo, o CEJUSC atua promovendo o exercício da cidadania e da propagação da valorosa cultura de paz dentro de uma comunidade em que atua, com reflexão e efetivação da resolução de desentendimentos.

A função do mediador já capacitado para utilização de técnicas e ferramentas autocompositivas, é garantir que a presença do CEJUSC seja efetivada no auxílio ao Poder Judiciário, ofertando à população o ingresso em sessões de resoluções de suas questões e garantindo que a prática da mediação esteja em constante qualificação. De acordo com Carvalho (2019), cada CEJUSC atua conforme suas competências delegadas para complementar as unidades judiciárias, por isso todos os centros possuem coordenador magistrado que gere a unidade e garante que seu ambiente físico seja acolhedor, criativo e adequado para recepcionar as partes, os advogados e os mediadores. A exigência desses espaços objetiva oferecer estrutura física para que a mediação ocorra com suas qualificações procedimentais e comunicativas, em razão de que as fases que compõem o procedimento conhecido pelo mediador, desde declaração de abertura à redação da ata encerrando o conflito, requerem universo privado, receptivo e dinâmico.

Exemplificando a relevância do CEJUSC na qualificação dos processos alternativos de mediação e conciliação, tem-se trabalho de caso de Vasconcelos et al (2020) na experiência vivenciada no Centro Judiciário de Olinda, no qual a prática do mediador revela-se eficaz em curto prazo, seguramente confidencial, guiado por flexibilidade e menos dispendioso para o Judiciário, assim como garantindo o desenvolvimento da concepção do litígio como caminho de resolução pacífica e satisfatória para ambas as partes. Além disso, os benefícios sentidos e apontados pela população atravessam a resolução do problema em si, mas se demonstra na manutenção da autonomia dos interesses dos litigantes, que de forma a não infringir o sentimentalismo cidadão, se viram em resoluções esclarecedoras e justas.

Dessarte, tendo no acesso à justiça um direito fundamental, assegurado pela Constituição de 88, evoluído conforme o desenvolvimento da sociedade e facilitado pela atuação dos métodos alternativos de resolução de conflitos, a criação das ferramentas de treinamento, como NUPEMECs e CEJUSCs, torna-se como marco legal da mediação e do mediador devidamente qualificado em guiar uma comunidade ao enfrentamento de suas problemáticas, fortalecendo o Judiciário e fomentando pacificação à população. Logo, é preciso portanto caminhar para a popularização da aplicação e dos benefícios dos meios alternativos pelas comunidades nacionais, atividade que é também de responsabilidade dos núcleos e dos centros judiciários, efetuada pelo mediador como agente habilitado das ferramentas autocompositivas que incentiva a transformação social através de uma nova concepção do conflito e nova abordagem de solucioná-lo (Bragança \& Souza, 2017).

\subsection{Competências autocompositivas do mediador na sua atuação resolutiva}

Segundo Fernandes (2018), a principal recomendação do CNJ é que o mediador avance no seu conhecimento e praticidade sobre as habilidades que aperfeiçoem as competências autocompositivas para uma real resolução e eficaz sessão de mediação, levando em consideração as características mais importantes durante esse desenvolvimento: escuta ativa, empatia e imparcialidade.

Assim, concebe-se o treinamento do mediador, o qual objetiva o desdobramento nas competências, composto pelas seguintes etapas: aquisição de conhecimento, aprimoramento da habilidade técnica e a atitude, coincidindo com o posicionamento do mediador no âmbito resolutivo de embates. Embasando-se assim nos teóricos já referenciados, no Manual de Mediação Judicial (2016) e na Resolução 125 do CNJ, será exposto detalhadamente as competências que qualificam o mediador e, consequentemente, a sessão de mediação.

De forma inicial, as competências emocionais do futuro mediador exigem seriedade e disposição de busca por parte do profissional. Denominada de Quociente Emocional (QE - Goleman, 1999), é constituída por elementos internos e externos, os 
quais são autoconsciência, que é a capacidade de perceber e identificar as emoções e os sentimentos sentidos em um determinado momento, a autogestão, a qual consiste na capacidade de compreender e gerenciar as emoções e os sentimentos percebidos. Os externos estão associados com a forma pela qual um determinado indivíduo se porta em suas relações interpessoais, podem ser subdivididos em empatia, que é a compreensão da realidade do seu interlocutor através da percepção dele, ou seja, a partir do conjunto de valores e crenças edificados na subjetividade da parte, e habilidades sociais, que se desenrolam pela capacidade de dialogar com pessoas integrantes de grupos com percepções distintas. Esse quociente está atrelado com a capacidade de adaptabilidade que um determinado indivíduo possui diante das adversidades da vida, ou seja, compreende a capacidade de resiliência e flexibilidade diante dos imprevistos vivenciados na existência, consistindo na forma pela qual um indivíduo visualiza um desafio (conflito), ou seja, qual a percepção dele e até que ponto está disposto a moldar o seu comportamento diante dessa dificuldade.

A competência cognitiva quanto ao conflito pode ser entendida como a forma pela qual a subjetividade do indivíduo se posicionará e avaliará determinada situação conflituosa. Assim, conforme teorização anteriormente abordada sobre o litígio, o conflito deve ser encarado como algo natural nas relações interpessoais e como um mecanismo de aperfeiçoamento desses relacionamentos.

Desse modo, as competências perceptivas correspondem à percepção da realidade externa e é estruturada com base no conjunto de ideias edificadas na sua consciência. O processo de autoconhecimento proporciona a compreensão dos pensamentos e emoções com o intuito de gerenciá-los e, esse aperfeiçoamento pessoal é obtido através de leituras edificantes e conhecimentos empíricos (de Brito \& de Brito, 2020). Essa autoanálise permite uma ampliação da percepção da consciência que poderá visualizar a realidade fática de uma forma pacífica e harmônica com o seu semelhante.

Outras competências relevantes são as comunicativas, das quais a habilidade de se comunicar assertivamente com o interlocutor se faz necessária durante a mediação. A Comunicação Não Violenta de Marshall Rosenberg (2006), proporciona habilidades em relação à linguagem e à comunicação, permitindo que seu usuário saiba expressar os seus pensamentos, sem perder a cordialidade e a humanidade, em situações conflituosas ou adversas. Assim como aperfeiçoa a expressão, a CNV também permite uma melhoria na capacidade de audição do seu usuário, já que a sua metodologia está associada com a escuta empática em relação a fala do interlocutor.

Na mediação, a competência do pensamento criativo é relevante no momento do brainstorm de geração de opções distintas de ganhos mútuos para as partes conflitantes. Essas possibilidades de resoluções ao conflito são geradas na negociação integrativa ou baseada em princípios da escola de Harvad. A criatividade é importante para gerar inúmeras soluções que sejam mais satisfatórias do que a manifestação inicial de cada negociante, e através do discernimento consciente consubstanciado no pensamento crítico em relação às opções geradas, as partes poderão escolher a resolução que mais compatibilize os interesses de ambas.

\section{Considerações Finais}

Concluindo o debate acerca da qualidade do treinamento do mediador judicial como relevante para o pleno avanço do acesso à justiça de forma igualitária e pacificadora, pode-se perceber que a evolução histórica e teórica da definição de acesso à justiça foi intrínseca para a criação de novas percepções de conceber o conflito como resultado da convivência em sociedade.

Além disso, essa obtenção de causa justa perpassou por fatores individuais, coletivos e de grupos específicos que compõe a sociedade como um todo, pois o litígio surge no desentendimento de interesses que se chocam e que, nem sempre, podem ser analisadas de forma subjetiva pela letra da lei, o que torna precária a harmonização social após findado o ato judiciário. Nisso, observou-se que os métodos adequados de resolução de litígios foram ganhando espaço cada vez que avançava o esgotamento do Poder Judiciário e a materialização da margem social que não alcançava plena satisfação nas ações judiciais.

Logo, os métodos autocompositivos foram sendo embasados cientificamente com reflexões, pesquisas e teorias para 
que sua atuação não só atingisse o fator final do conflito, mas que esse caminho para a resolução fosse trilhada de forma pacificadora e satisfatória para as partes envolvidas.

Dessa forma, a estruturação dessa extensão do judiciário passou a ser orientada e guiada por resolutivas, como publicações do Conselho Nacional de Justiça com a Resolução 125 de 2010, assim como a publicação do Manual de Mediação Judicial e suas conseguintes edições. Nelas toda a base necessária para a formação, manutenção e supervisão dos métodos autocompositivos se faz eficiente em todo o território nacional, sendo de responsabilidade primária do NUPEMEC a normatização dos treinamentos para mediadores judiciais, de forma que haja padronização de qualidade na atuação da mediação e conciliação, sendo também de responsabilidade do CEJUSC, atuante de forma regional nos Estados Federativos, a aplicação efetiva da mediação dentro das comunidades locais.

Com isso, é possível afirmar que o programa de treinamento do mediador judicial, totalmente resguardado e orientado, pode valorizar os métodos adequados como porta de acesso à justiça, sendo efetiva em diferentes âmbitos sociais e facilitando o encargo judiciário. Assim sendo, pode-se concluir que toda a organização que cerca o mediador é essencialmente qualificativa no que tange a busca pelo desenvolvimento do pleno acesso à justiça pela sociedade de forma igualitária e satisfatória, onde as competências do mediador são adequadamente formadas, ampliadas e aptas para a prática de sessões harmônicas diante dos conflitos existentes na sociedade, viabilizando a educação da cultura de paz e satisfazendo os usuários do judiciário em busca de justiça e resoluções.

\section{Referências}

Albuquerque, D. O. (2017). O marco legal da mediação no brasil e o mediador judicial, sua capacitação e formação continuada-o exemplo do NUPEMECTJRS. A mediação no poder Judiciário; Estado, do Rio Grande.

BRASIL. (1988) Dos Princípios Fundamentais. Constituição da República Federativa do Brasil.

BRASIL. (2010). Conselho Nacional de Justiça. Resolução $N^{o} 125$, de 29 de novembro de 2010. Acesso em: https://atos.cnj.jus.br/atos/detalhar/156.

Braganca, F; Souza, C. F. de. (2017). As etapas de institucionalização da mediação no Brasil. Revista de Formas Consensuais de Solução de Conflitos, 3(1), 0115 .

Bush, R. A. \& Baruch, J. P. F. (2004). A promessa de mediação: a abordagem transformadora do conflito. John Wiley \& Sons.

Calcaterra, R. A. (2002). Mediación Estratégica. Barcelona: Gedisa.

Cappelletti, M. \& Garth, B. (1988). Acesso à justiça. SA Fabris

Carvalho, R. M. (2019). CEJUSC/JT: uma nova realidade, um novo caminho: análise dos avanços e perspectivas da política pública de conciliação em âmbito trabalhista. Revista do Tribunal Regional do Trabalho da 10 ${ }^{a}$ Região, 23(2), 111-120.

Camargo, D. A. (2017). A mediação comunitária como ferramenta de acesso à justiça e desenvolvimento no espaço local. Revista Brasileira de Políticas Públicas, 7(1).

Corrêa, I. Z. N.; da Câmara Auler, R. R. \& Pontes Filho, R. P. (2021). Acesso à justiça por meio da mediação comunitária como fator de emancipação social no contexto do acesso à justiça nos interiores do amazonas. Revista Científica do UniRios, 135.

de Brito, M. F. G., \& de Brito, A. H. (2020). Mediação: A importância da psicologia no meio jurídico. Brazilian Journal of Development, 6(9), 73412-73422.

Dos Santos, E. C. A. \& Borges, P. P. (2018). Mediação como instrumento para solução de conflitos: direito fundamental de aces so à justiça. Revista de Direito Brasileira, 20(8), 146-173.

Fernandes, I. B. A. \& Gonçalves, F. J. M. (2018). A formação de mediadores e conciliadores no Poder Judiciário do Estado do Ceará. Revista Paradigma, Ribeirão Preto-SP, a. XXIII, 27(1), 215-237

Filpo, K. P. L. (2016). Mediação judicial. Mauad Editora Ltda.

Fisher, L. (1969). Third Party Neutrals: Issues in Training, apud Schnitman, D. F. \& Littlejohn, S. (1999). Novos Paradigmas em Mediação. Porto Alegre: Artmed, 372.

Gago, C. P. \& Sant'anna, P. F. (2017). O protagonismo na linguagem na mediação familiar judicial. Revista Brasileira de Lingüística Aplicada, 17(4).

Goleman, D. (1999). Trabalhando com a inteligência emocional. Objetiva. 
Research, Society and Development, v. 11, n. 1, e25811124665, 2022

(CC BY 4.0) | ISSN 2525-3409 | DOI: http://dx.doi.org/10.33448/rsd-v11i1.24665

Lages, C. G. \& Diz, J. B. M. (2018). Revisitando a concepção de acesso à justiça a partir da obra de Cappelletti e Garth. Revista Jurídica (FURB), 22 (47), 219 252.

Leitão, L. P. B. (2021). Reflexão crítica sobre a implementação da mediação judicial no Brasil: uma proposta de aprimoramento do instituto por meio dos parâmetros da mediação pré-processual. Repositório Unichristus.

Macedo, E. H. (2017). Cidadania e dignidade humana na dimensão do processo: Humanização do processo. Revista de Direito Brasileira.

Martins, J. R., \& Dobler, E. H. (2020). Mediação como direito fundamental de acesso à justiça e construção da cidadania por meio da internet em tempos de pandemia. Stéfani Reimann Patz Thami Covatti Piaia (Organizadores), 99.

Mussio, R. A. P \& De Souza S. A. B. (2017). (Inter) mediação latente de conflitos e comunicação não-violenta na atividade secretarial. Perspectivas em Gestão \& Conhecimento, 7(2), 214-228.

Neto, Z. G.; Lima, T. G. B. \& Benevides, J. R. (2017). O desafio do acesso à justiça no brasil e a comparação no direito português. Revista Direito e Justiça: reflexões sociojurídicas, 17 (28), 145-156.

Paraventi, L.; Scaff L.; Cord, D. \& Oltramari L. (2017). Mediação grupal como estratégia de ressignificação da queixa escolar. Revista Pesquisas e Práticas Psicossociais, 12(3), 14.

Pinho, H. D. B. de. (2011). O novo CPC e a mediação: Reflexões e ponderações. Revista de informação legislativa, 48(190), 219-235.

Rosenberg, M. B. (2006). Comunicação não-violenta: técnicas para aprimorar relacionamentos pessoais e profissionais. Editora Agora.

Sales, L. \& Rabelo, C. (2009). Meios consensuais de solução de conflitos Instrumentos de democracia. Revista de Informação Legislativa Brasília, $46,81$.

Sales, L. M. M. \& Andrade, M. D. de. (2011). A mediação de conflitos como efetivo contributo ao Poder Judiciário brasileiro. Revista de informação legislativa, 48,192 .

Six, J-F. (2001). Dinâmica da Mediação. Del Rey.

Souza, L. M. de. (2015). Mediação de conflitos: novo paradigma de acesso à justiça.

Suter, J R., \& Cachapuz, R. R. (2017). A mediação como instrumento fortalecedor do acesso à justiça e da democracia na resolução de conflitos familiares. Scientia Iuris, 21(2), 237-260.

Teixeira, J. A., Rêgo, M. C. B., \& Silva, A. I. D. (2020). Inovação no Judiciário: coprodução, competências e satisfação do usuário na mediação judicial. Revista de Administração Pública, 54, 381-399.

Vasconcelos, Y. L., da Silva, A. C., da Silva, A. C. B., Sayão, S. C., \& Luna, M. J. M. (2020). Tribunais do Trabalho fomentando a cultura de paz: sistematização das técnicas utilizadas com base em um relato de experiência. International Journal of Development Research, 10(12), 42966-42971.

Vasconcelos, Y. L, da Silva, A. C., Remígio, A. S. N. M., de Lima Albuquerque, J., \& Luna, M. J. M. (2020). A mediação judiciária trabalhista a partir da experiência do CEJUSC-JT / Olinda: um estudo de caso. Research, Society and Development, 9 (10), e5359108743-e5359108743. 